\title{
Clear Cell Variant or Clear Cell Component?
}

\author{
Takashi Muramatsu ${ }^{1)}$, Sadamitsu Hashimoto ${ }^{2)}$ and Fumio Ide Id, $^{3,4)}$ \\ ${ }^{1)}$ Department of Endodontics and Clinical Cariology, Tokyo Dental College, \\ 2-9-18 Misaki-cho, Chiyoda-ku, Tokyo 101-0061, Japan \\ 2) Laboratory of Biology, Tokyo Dental College, \\ 2-9-7 Kanda-Surugadai, Chiyoda-ku, Tokyo 101-0062, Japan \\ ${ }^{3)}$ Division of Oral Pathology, Department of Diagnostic and Therapeutic Sciences, \\ Meikai University School of Dentistry, \\ 1-1 Keyakidai, Sakado, Saitama 350-0283, Japan \\ 4) Department of Diagnostic Pathology, Tsurumi University School of Dental Medicine, \\ 2-1-3 Tsurumi, Tsurumi-ku, Yokohama, Kanagawa 230-8501, Japan
}

Received 28 December, 2015/Accepted for publication 12 January, 2016

\section{To the Editor}

We enjoyed reading the case report by Yamamoto et al. . $^{4}$ describing mucoepidermoid carcinoma (MC) with clear cell components. The paper once again aroused our interest in what has become a controversial issue in the field of pathology regarding the clear cell variant of MC; that is, how it should be defined, and how it should be diagnosed.

Histologically, MC consists of a mixture of mucus-producing, intermediate, and squamous cells. Depending on the constituent cells, MCs display several variants, such as oncocytic, sclerosing, and clear cell $^{1)}$. In general, an appropriate diagnosis can easily be made based on the morphological features typical to each specific type of tumor (Fig. 1c), even if it is predominantly composed of clear cells (Figs. 1a, 1b), as hopefully was evident from our previous case report ${ }^{3)}$. However, it seems that the histological definition of the clear cell variant of MC remains to be agreed upon. Although oral pathologists accept the concept of distinguishing between the clear cell variant of MC and an MC with clear cell components, considerable controversy exists regarding how they should be defined. Therefore, when focal clear cells appear in MC, oral pathologists face difficulty in arriving at a diagnosis. Yamamoto et al. cited three histological factors and histochemical staining for diagnosis with reference to an earlier report ${ }^{2}$. However, if we accept a diagnosis of the clear cell variant when clear cells only comprise a minor component of the MC, then the number of published reports on this variant automatically increases greatly. Therefore, the term "clear cell variant of MC" needs to be carefully used in indicating such lesions.

In conclusion, the definition of the clear cell variant of MC remains elusive and controversial. Evidence is currently insufficient to distinguish clear cell components from the clear cell variant. This indicates the need to arrive at clear-cut descriptions of each variant of MC so that all pathologists can share the same workable definition. 

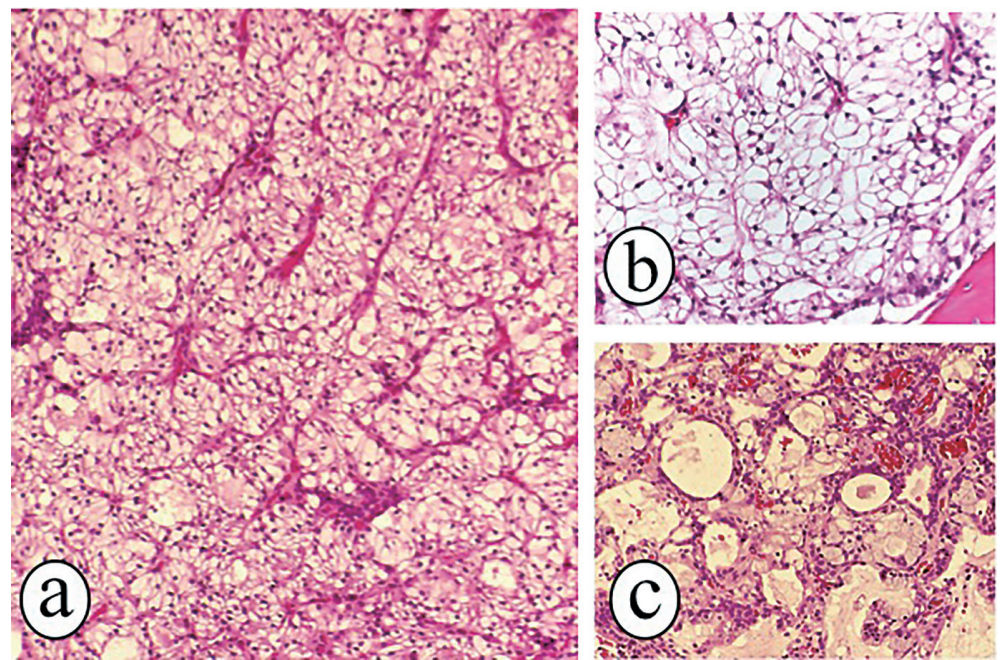

Fig. 1 Representative histopathological findings of clear cell variant of mucoepidermoid carcinoma in 51-year-old Japanese man

a: Tumor was composed of solid sheet of clear cells with scanty fibrous stroma.

b: At higher magnification, tumor cells were mainly composed of clear cells; some cells had eosinophilic granules in cytoplasm.

c: Mucous, basaloid, intermediate, and squamous patterned cells, suggesting typical mucoepidermoid carcinoma, were all observed in same specimen. Cyst formation was also observed.

\section{References}

1) Bernes L, Eveson JW, Reichart P, Sideansky D (Eds) (2005) World Health Organization Classification of Tumours, Pathology and Genetics Head and Neck Tumours, pp.219220, IARC Press, Lyon.

2) Ogawa I, Nikai H, Takata T, Yasui R (1992) Clearcell variant of mucoepidermoid carcinoma: report of a case with immunohistochemical and ultrastructural observations. J Oral Maxillofac Surg 50:906-910.

3) Shigematsu S, Suzuki K, Suga K, Koeda H, Saito C, Muramatsu T (1997) A case of clear cell variant of mucoepidermoid carcinoma in the maxillary sinus. Jpn J Oral Maxillofac
Surg 43:188-190. (in Japanese)

4) Yamamoto N, Watabe Y, Iwamoto M, Matsuzaka K, Shibahara T (2014) A case of mucoepidermoid carcinoma with clear cell components occurring in retromolar region. Bull Tokyo Dent Coll 55:25-31.

\section{Correspondence:}

Dr. Takashi Muramatsu

Department of Endodontics and

Clinical Cariology,

Tokyo Dental College,

2-9-18 Misaki-cho, Chiyoda-ku,

Tokyo 101-0061, Japan

E-mail: tmuramat@tdc.ac.jp 